\title{
Betaine Transport in Kidney and Liver: Use of Betaine in Liver Injury
}

\author{
Stephen A. Kempson Komi Vovor-Dassu Christopher Day \\ Department of Cellular and Integrative Physiology, Indiana University School of Medicine, \\ Indianapolis, Indiana, USA
}

\author{
Key Words \\ Betaine/GABA transporter • Alcohol $\bullet$ Methyl donor $\bullet$ Hepatocyte $\bullet$ MDCK
}

\begin{abstract}
Betaine, also known as trimethylglycine, is an important human nutrient obtained from a variety of foods and also can be synthesized from choline. Betaine is much more abundant in kidney and liver compared to other mammalian organs. The principal role of betaine in the kidney is osmoprotection in cells of the medulla and it enters these cells via the betaine $/ \gamma$-aminobutyric acid (GABA) transporter protein (BGT1), which is upregulated by hyperosmotic stress. This process has been studied in great detail. In liver, the main role of betaine is a methyl donor in the methionine cycle. However, recent studies showed that BGT1 is much more abundant in liver compared to kidney medulla. Despite this, the role of BGT1 in liver has received little attention. Entry of betaine into liver cells is a necessary first step for its action at the cellular level. Increased interest in betaine has developed because of a number of therapeutic uses. These include treatment of nonalcoholic fatty liver and hyperhomocysteinemia, a risk factor for atherosclerotic disease. Several important questions need to be addressed to better understand the potential of betaine as a therapeutic agent for other liver diseases, such as alcohol-induced injury. Heavy alcohol consumption is the most common cause for liverrelated deaths and altered liver metabolism may contribute to hepatic, vascular, coronary, and cerebral diseases.
\end{abstract}




\section{Introduction}

Betaine is the trimethyl derivative of the amino acid glycine and is sometimes termed trimethylglycine. It is highly water-soluble and exists as the zwitterion $\left(\mathrm{CH}_{3}\right)_{3} \mathrm{~N}^{+} \mathrm{CH}_{2} \mathrm{COO}^{-}$ at neutral $\mathrm{pH}$. Betaine filtered at the glomerulus is conserved by reabsorption along the nephron. The low fractional excretion of betaine was reported to be less than $6 \%$, indicating that filtered betaine is nearly completely reabsorbed from the tubular lumen somewhere along the nephron [1]. One site is the proximal tubule, where betaine can be reabsorbed by cotransport with either $\mathrm{Na}^{+}$or $\mathrm{H}^{+}$across the luminal plasma membrane. The cotransporters were found to be independent of the presence of chloride ions and both were inhibited by L-proline [2]. Both the convoluted and straight segments are likely involved in the recovery of filtered betaine [1]. The specific sodium-dependent betaine transport system in the straight segment may be the sodium-dependent imino acid transporter (SIT1), a member of the solute carrier (SLC) 6A sodium/solute symporter family. SIT1 (SLC6A20) exhibits some properties of the long-sought IMINO system for proline $[3,4]$.

\section{Betaine and kidney}

Betaine in the kidney functions principally as an osmoprotectant. The always high (but changing) osmolarity in the interstitium of the inner medulla is essential for the normal process of water reabsorption and urine concentration [5]. The high osmolarity contributes to a 'hostile environment' [6] and an essential strategy for cellular survival is to accumulate osmotically active organic compounds. These balance the high extracellular osmolarity and preserve cell volume without interfering with cell function. This aids survival because cell shrinkage would facilitate apoptosis [7]. Betaine is an important osmolyte in the kidney and in other tissues such as brain. Betaine is present in blood plasma at about $0.1 \mathrm{mM}$ and is derived from the diet and choline metabolism in the liver [8-11]. In contrast to reabsorption of filtered betaine by the proximal tubule in the cortex, cells in the kidney medulla accumulate betaine primarily from the blood supply and via the sodium and chloride coupled betaine $/ \gamma$-aminobutyric acid GABA transport system (BGT1). This is an integral membrane protein localized in the basolateral plasma membrane and is a member of the SLC6A family (SLC6A12). BGT1 specific mRNA is predominantly present in the thick ascending limb of Henle's loop and in inner medullary collecting ducts and is osmosensitive [12]. Activation of BGT1 gene transcription in response to hyperosmotic stress suggests that the BGT1 transporter is primarily responsible for cellular betaine accumulation in these segments during osmotic stress. BGT1 expression is regulated by the transcription factor known as tonicity-responsive enhancer binding protein (TonEBP), also called nuclear factor of activated T-cells (NFAT5). This has been studied in great detail by Burg, Kwon and colleagues and has been reviewed elsewhere [13-18]. The renal BGT1 protein cotransports betaine (or GABA) with both $\mathrm{Na}^{+}$and $\mathrm{Cl}^{-}$ions $[19,20]$, and is upregulated more than 10 -fold during hyperosmotic stress (500 m0sm) in cultured MDCK kidney cells [21, 22]. In our own unpublished studies, as expected, hypertonic stress for $24 \mathrm{hr}$ increased the betaine content of MDCK cells from $287 \pm 81$ in controls to $1276 \pm 114 \mathrm{nmol} / \mathrm{mg}$ protein $(\mathrm{P}<0.002, \mathrm{n}=3)$. The 4-5 fold increase agrees closely with previously published data for these same cells [23].

Hyperosmotic upregulation of BGT1 is relatively slow, requiring almost $24 \mathrm{~h}$ for completion in cultured cells. In contrast, as shown recently, BGT1 is downregulated acutely by endocytosis triggered by extracellular adenosine, ATP or activators of protein kinase C $[24,25]$. There is also recent evidence of acute upregulation of BGT1 transport in frog oocytes mediated by a specific kinase, possibly due to increased retention of BGT1 protein after insertion in the plasma membrane [7]. Although BGT1 has a higher affinity for GABA, its primary role in the kidney is betaine transport $[19,26]$, while GABA is likely the primary substrate for transport by brain BGT1 [13, 27]. 

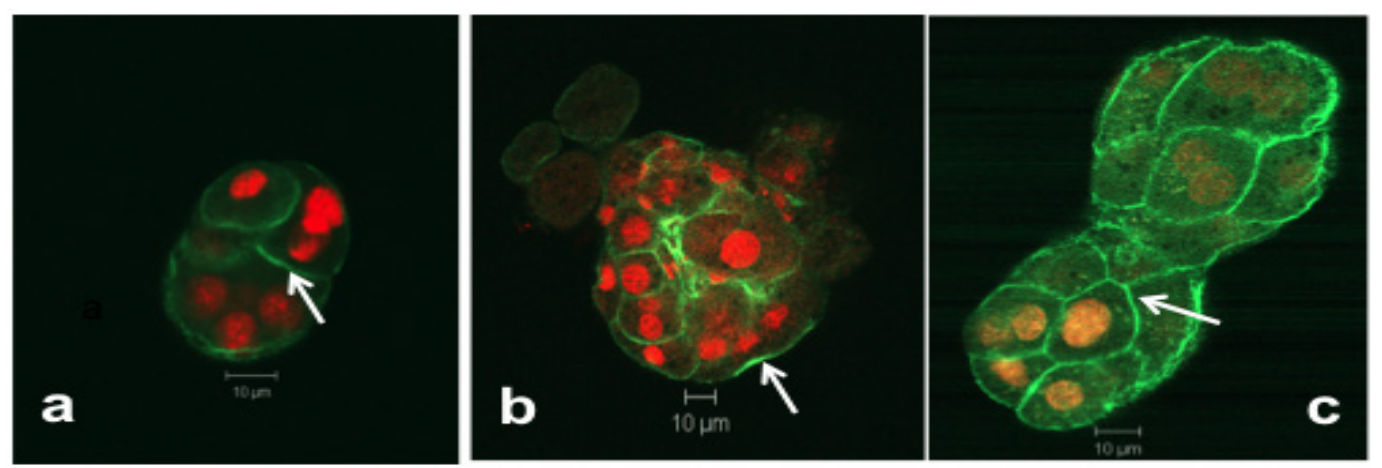

Fig. 1. In primary cultures of hepatocytes, BGT1 was localized in the plasma membrane. Hepatocytes were isolated from mouse liver by collagenase perfusion, as described in detail in [34], and were plated for $24 \mathrm{~h}$ in isotonic Williams E growth medium (Sigma-Aldrich) containing 10\% fetal calf serum, $100 \mathrm{IU} / \mathrm{ml}$ penicillin, and $100 \mu \mathrm{g} / \mathrm{ml}$ streptomycin, $1 \%$ glutamine, $1 \%$ nonessential amino acids [34]. Cells were fixed in $4 \%$ paraformaldehyde and immunostained for mouse BGT1 using affinity purified antibodies provided by Prof NC Danbolt (University of Oslo, Norway) diluted 1:100. Localization of BGT1 antibody was detected with goat anti-mouse IgG conjugated to FITC (Jackson ImmunoResearch), diluted 1:100. Nuclei were stained with propidium iodide. Images were captured with a Zeiss confocal microscope and panels a, b, and c represent different hepatocyte preparations. Arrows indicate the plasma membrane location of BGT1 in the majority of cells under isotonic conditions. In marked contrast, BGT1 is entirely intracellular in renal MDCK cells maintained in isotonic growth medium, and is only localized in the plasma membrane during hypertonic stress [22].

\section{Betaine and liver}

Compared to the wealth of investigative studies on renal BGT1, there is scant information on the liver betaine transporter. A liver-specific isoform of BGT1 has been cloned [28] and BGT1 mRNA is expressed in liver tissue [13]. However, the role of liver BGT1 has received little attention, in part because it was thought to be absent from hepatocytes and only present in less abundant cell types, such as Kupffer and endothelial cells. [29-31]. This is surprising, given that TonEBP is also expressed in liver cells and, importantly, is transcriptionally active at normal osmolarity $[13,32]$. More recent data from the Danbolt laboratory showed that liver BGT1 protein is much more abundant than kidney BGT1 in the mouse [33] and our own unpublished studies on hepatocytes from mouse liver confirmed the presence of BGT1 protein. In hepatocytes, isolated by collagenase perfusion [34], we observed that BGT1 was localized to the plasma membrane under iso-osmotic $(280 \mathrm{mOsmol} / \mathrm{kg})$ conditions (unpublished data, see Fig. 1), in marked contrast to renal medullary cells, where BGT1 remains intracellular until the onset of hyperosmotic stress [35]. However, the unexpected plasma membrane location in hepatocytes is consistent with the reported transcriptional activity of TonEBP at normal osmolarity (see above), suggesting that betaine transport is always 'switched on'. Further, we found that hepatocyte BGT1 was functional under isoosmotic conditions as indicated by cell uptake of $\left[{ }^{14} \mathrm{C}\right]$ betaine in the presence of extracellular sodium and chloride ions. $\mathrm{Na}^{+} / \mathrm{Cl}^{-}$-dependent transport of betaine was sensitive to removal of extracellular $\mathrm{Na}^{+}$and to inhibition by quinidine and nipecotic acid (unpublished data, see Fig. 2), similar to the activity of the renal BGT1 transporter [35]. Hepatocyte betaine transport also was partially inhibited by 100 -fold excess of methylaminoisobutryic acid and carnitine (Fig. 2) raising the possibility that, at least under experimental conditions, some betaine uptake utilized the $\mathrm{Na}^{+}$-dependent system A amino acid transporter (ATA2) [36] and the ubiquitous $\mathrm{Na}^{+} / \mathrm{L}$-carnitine cotransporter (OCTN2) [37]. The relative abundance of these transporters relative to BGT1 in liver remains unknown, but it appears there may be multiple pathways for hepatocytes to accumulate betaine. This reinforces the importance of betaine in liver and its role as a methyl donor. The betaine content of liver (and kidney) 


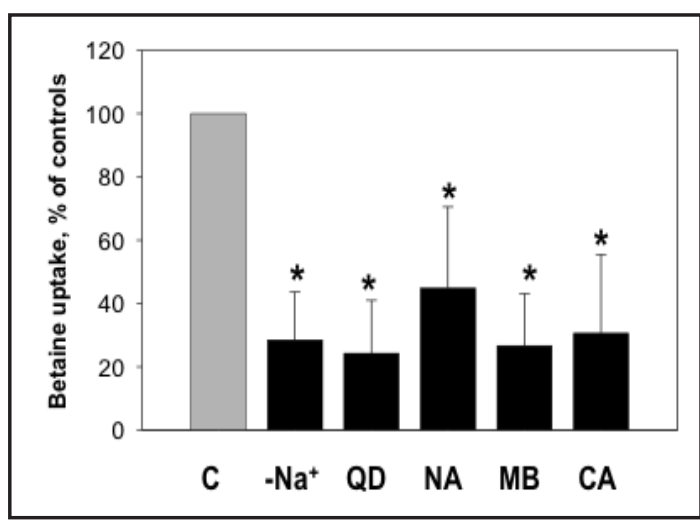

Fig. 2. Betaine transport in hepatocytes. Under isotonic conditions, $\mathrm{Na}^{+} / \mathrm{Cl}^{-}$-dependent betaine uptake by hepatocytes was inhibited by omission of $\mathrm{Na}^{+}$ (replaced by methyl-D-glucamine), or by 100 -fold excess (1.0 mM final concentration) of quinidine (QD), nipecotic acid (NA), $\alpha$-methylaminoisobutyric acid (MB) or carnitine (CA). Hepatocytes were isolated from mouse liver and grown in monolayer culture for $24 \mathrm{~h}$ prior to use for transport studies. Uptake of $\left[{ }^{14} \mathrm{C}\right]$ betaine $(0.01 \mathrm{mM})$ and other experimental procedures were the same as described previously in detail for transport studies in renal MDCK cells $[21,24,25]$. Data are mean \pm SD of 3-5 experiments, and all experimental groups are significantly different ( $\mathrm{p}<0.01$, one-way ANOVA) from controls (C).

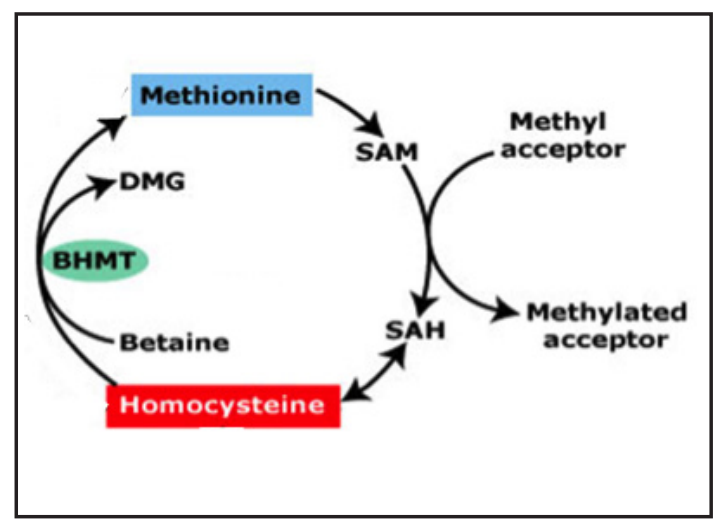

Fig. 3. The methionine cycle in liver. Homocysteine, a risk factor for cardiovascular problems, is converted to methionine by the BHMT enzyme, which transfers a methyl group from betaine to homocysteine. Loss of a methyl group converts betaine to DMG. Methionine is converted to SAM, which methylates numerous acceptor molecules. An additional pathway for methionine production from homocysteine (not shown) is the use of folate as a methyl donor mediated by methionine synthase (folate cycle). Chronic ethanol consumption has been shown to impair the activity of methionine synthase (see text). BHMT, betaine-homocysteine S-methyltransferase. DMG, dimethylglycine. SAM, S-adenosylmethionine. SAH, S-adenosylhomocysteine.

greatly exceeds that of other organs, at least in the rat, and plasma betaine is conserved by very efficient renal reabsorption $[11,38]$.

Just as BGT1 is most abundant in liver compared to other tissues, so is betainehomocysteine S-methyltransferase (BHMT) [33]. This enzyme converts homocysteine to methione by transferring a methyl group from betaine and in this reaction betaine is converted to dimethylglycine (DMG, Fig. 3). In an alternative pathway to form methionine (not shown), folate also can serve as a methyl donor and the methyl group is transferred to homocysteine by the enzyme methionine synthase with vitamin $\mathrm{B}_{12}$ as a cofactor [39]. The need for two pathways may have arisen because methionine is metabolized to $S$-adenosylmethionine (SAM) which is produced and consumed in the liver at a rate estimated to be 6-8 g/day [39]. About $85 \%$ of all methylation reactions occur in the liver [40] and SAM is the universal methyl donor for methylation of diverse acceptor molecules (e.g. DNA, RNA, histones, phospholipids). During these reactions, SAM is converted to S-adenosylhomocysteine (SAH) (Fig. 3). SAH is then hydrolyzed to adenosine and homocysteine. The latter is normally used to reform methionine, conserve methionine to produce more SAM, and prevent homocysteine toxicity.

Abnormal methionine metabolism in liver is one result of alcohol abuse and appears to be a major factor in the pathogenesis of alcoholic liver disease. For example, the ethanolinduced decrease in SAM levels in liver leads to weakening of defense mechanisms, such as production of glutathione, the principal antioxidant [39], and other oxyradical scavengers [41]. In alcoholics and chronic ethanol-fed animals, hepatic SAM is depleted while SAH is increased, due in part to reduced activity of the methionine synthase. This leads to elevated levels of homocysteine in plasma. The liver SAM/SAH ratio indicates the capacity for methylation [38] and a decrease in the SAM/SAH ratio is indicative of disrupted 
Fig. 4. Decreased liver betaine content after EtOH drinking in mice. Nine mice (C57BL/6J male 6-8 wk-old) per group were fed isocaloric liquid diets \pm ethanol (Lieber-DeCarli formula) for four weeks, as described previously in detail [68]. The two groups were pair-fed. In the ethanol-fed group, ethanol accounted for $27.5 \%$ of the total caloric intake [68]. Liver tissue was kindly provided by Dr Suthat Liangpunsakul (Gastroenterology Division, Indiana University School of Medicine, Indianapolis), and metabolites were

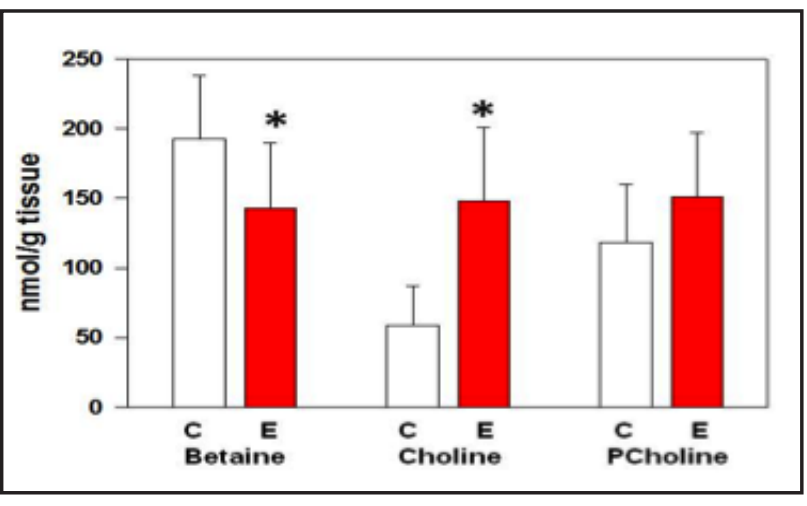
measured in flash-frozen liver samples by liquid chromatography-mass spectrometry at the University of North Carolina at Chapel Hill by Dr KA DaCosta. ${ }^{*} \mathrm{P}<0.05$, one-way ANOVA. C, controls. E, ethanol-fed. Pcholine, phosphatidylcholine.

transmethylation reactions [42]. In this situation, betaine provides an alternative pathway (Fig. 3) to methylate homocysteine, form methionine and maintain a high SAM/SAH ratio $[10,43-45]$. Consistent with increased use of betaine in this pathway, methionine synthase is depressed and plasma DMG (Fig. 3) is elevated during alcoholic liver disease in humans [46]. Another study also showed that ethanol feeding to rats impaired methionine synthase but proposed that the concomitant increase in the BHMT pathway utilizing betaine was sufficient to maintain SAM levels in the normal range. Further, dietary betaine supplementation increased SAM levels, especially in alcohol-fed animals [47]. More recent studies in rats [41, 48] confirmed that supplementation of dietary betaine was hepatoprotective in ethanol-fed animals. Hepatic SAM, cysteine and glutathione were reduced by ethanol feeding and all changes were reversed by subsequent betaine feeding. In a different context, it is interesting to note that homocysteine levels were elevated in liver cirrhosis which was attributed to downregulation of BHMT enzyme activity (Fig. 3), suggesting an association between deranged betaine metabolism and liver disease [49].

Our own studies in mice fed ethanol for four weeks, as part of a liquid diet, showed a $27 \%$ decrease in liver betaine content complemented by a $250 \%$ increase in content of the precursor choline, suggesting choline conversion to betaine was impaired. Phosphatidylcholine content was not significantly changed (unpublished data, see Fig. 4). A decrease in liver betaine after alcohol drinking also was reported by another group [50]. This raises some fundamental questions about betaine transport in liver. For example, is BGT1 the principal pathway for betaine uptake by hepatocytes, or are other transport systems (e.g. ATA2 or OCTN2) also important? What is the relative contribution of betaine transport compared to betaine synthesis in maintaining liver betaine content, and what is the effect of ethanol feeding on both processes? Is liver injury more severe when BGT1 is absent? Are tissue betaine levels during ethanol feeding restored by supplementation of dietary betaine, and if so, does this lead to reversal of liver injury? What happens to betaine transporters during this process? Hepatocytes in culture and the BGT1 knockout mouse, recently developed by Danbolt and colleagues [27], should be useful model systems for answering some of these important questions.

\section{Conclusion}

Heavy ethanol consumption interferes with myocardial metabolism and leads to increased risk of arrhythmias and sudden cardiac death [51-53], and the toxic action on brain and liver function has long been recognized. Alcohol use remains the most common cause for liver-related death and alcoholic liver disease is a major public health problem [54]. As many 
as 2 million people in the US have alcohol-related liver disorders such as fatty liver, cirrhosis and cancer [55-57]. In humans, dietary betaine was found to improve liver function in fatty liver disease, including steatohepatitis [43, 48, 58, 59]. In animals and cultured cells, betaine had protective effects against liver injury, but the mechanism has not been determined [45, 60]. Clinical trials on the effectiveness of SAM for treating alcoholic liver disease have been inconclusive [10]. There has been a resurgence of interest in the therapeutic use of betaine for reducing alcohol-induced liver injury and a broad spectrum of cellular mechanisms have been proposed [59, 60-63]. Betaine is much less expensive than SAM, but few trials in humans have been reported and the data are limited [58,64]. Exogenous betaine has already been used clinically to lower plasma homocysteine levels in humans since homocysteine is an independent risk factor for atherosclerotic disease [65, 66] and dementia [67]. It has been used extensively in animal and livestock nutrition [62]. Given the potential for safe and inexpensive improvement of human alcoholic liver disease, and possibly others such as liver cirrhosis, further studies of the role of betaine and its transport and metabolism at the cellular level are needed to better understand the intracellular mechanisms of betaine action in normal and diseased liver.

\section{Conflict of Interests}

No conflicts of interest to disclose.

\section{Acknowledgements}

The authors' work was supported in part by the American Heart Association Midwest Affiliate. We thank Professor NC Danbolt and Dr Y Zhou (University of Oslo, Norway) for many helpful discussions.

\section{References}

1 Pummer S, Dantzler WH, Lien Y-HH, Moeckel GW, Völker K, Silbernagl S: Reabsorption of betaine in Henle's loops of rat kidney in vivo. Am J Physiol - Renal Physiol 2000;278:F434-F439.

2 Wunz TM, Wright SH: Betaine transport in rabbit renal brush-border membrane vesicles. Am J Physiol 1993;264:F948-F955.

- 3 Takanaga H, Mackenzie B, Suzuki Y, Hediger MA: Identification of Mammalian Proline Transporter SIT1 (SLC6A20) with Characteristics of Classical System Imino. J Biol Chem 2005;280:8974-8984.

4 Bröer S: The SLC6 orphans are forming a family of amino acid transporters. Neurochem Int 2006;48:559567.

5 Delgado-Reyes CV, Garrow TA: High sodium chloride intake decreases betaine-homocysteine S-methyltransferase expression in guinea pig liver and kidney. Am J Physiol Reg Integ Comp Physiol 2005;288:R182-R187.

6 Neuhofer W, Beck F-X: Cell survival in the hostile environment of the renal medulla. Annu Rev Physiol 2005;67:531-555.

7 Almilaji A, Munoz C, Hosseinzadeh Z, Lang F: Upregulation of Na+,Cl- -coupled betaine/gamma-aminobutyric acid transporter BGT1 by tau tubulin kinase 2. Cell Physiol Biochem 2013;32:334-343.

-8 Burg MB: Molecular basis of osmotic regulation. Am J Physiol Renal Physiol 1995;268:F983-F996.

-9 Zhang F, Warskulat U, Wettstein M, Haussinger D: Identification of betaine as an osmolyte in rat liver macrophages (Kupffer cells). Gastroenterology 1996;110:1543-1552.

10 Purohit V, Abdelmalek MF, Barve S, Benevenga NJ, Halsted CH, Kaplowitz N, Kharbanda KK, Liu Q-Y, Lu SC, McClain CJ, Swanson C, Zakhari S: Role of S-adenosylmethionine, folate, and betaine in the treatment of alcoholic liver disease: summary of a symposium. Am J Clin Nutr 2007;86:14-24. 
11 Slow S, Lever M, Chambers ST, George PM: Plasma dependent and independent accumulation of betaine in male and female rat tissues. Physiol Res 2009;58:403-410.

12 Miyai A, Yamauchi A, Moriyama T, Kaneko T, Takenaka M, Sugiura T, Kitamura H, Ando A, Tohyama M, Shimada S, Imai E, Kamada T: Expression of betaine transporter mRNA: its unique localization and rapid regulation in rat kidney. Kidney Int 1996;50:819-827.

13 Zhang Z, Ferraris JD, Brooks HL, Brisc I, Burg MB: Expression of osmotic stress-related genes in tissues of normal and hyposmotic rats. Am J Physiol Renal Physiol 2003;285:F688-693.

$\checkmark 14$ Ferraris JD, Burg MB: Tonicity-dependent regulation of osmoprotective genes in mammalian cells. Contrib Nephrol 2006;152:125-141.

15 15. Burg MB, Ferraris JD: Intracellular Organic Osmolytes: Function and Regulation. J Biol Chem 2008;283:7309-7313.

16 Kwon MS, Lim SW, Kwon HM: Hypertonic stress in the kidney: a necessary evil. Physiology 2009;24:186191.

17 Lee SD, Choi SY, Lim SW, Lamitina ST, Ho SN, Go WY, Kwon HM: TonEBP stimulates multiple cellular pathways for adaptation to hypertonic stress: organic osmolyte-dependent and -independent pathways. Am J Physiol - Renal Physiol 2011;300:F707-F715.

18 Zhou X, Wang H, Burg MB, Ferraris JD: High NaCl-induced inhibition of PTG (protein targeting to glycogen) contributes to activation of NFAT5 through attenuation of the negative effect of SHP-1 Am J Physiol- Renal Physiol 2013;305:F362-F369

19 Yamauchi A, Uchida S, Kwon HM, Preston AS, Robey RB, Garcia-Perez A, Burg MB, Handler JS: Cloning of a $\mathrm{Na}+$ - and $\mathrm{Cl}$ - -dependent betaine transporter that is regulated by hypertonicity. J Biol Chem 1992;267:649652.

20 Matskevitch I, Wagner CA, Stegen C, Broer S, Noll B, Risler T, Kwon HM, Handler JS, Waldegger S, Busch AE, Lang F: Functional characterization of the betaine/GABA transporter BGT-1 expressed in Xenopus oocytes. J Biol Chem 1999;274:16709-16716.

-21 Kempson SA: Differential activation of system A and betaine/GABA transport in MDCK cell membranes by hypertonic stress. Biochim Biophys Acta 1998;1372:117-123.

22 Kempson SA, Montrose MH: Osmotic regulation of renal betaine transport: transcription and beyond. Pflugers Arch Eur J Physiol 2004;449:227-234.

23 Nakanishi T, Balaban RS, Burg MB: Survey of osmolytes in renal cell lines. Am J Physiol 1988;255:C181-191.

24 Kempson SA, Edwards JM, Osborn M, Sturek M: Acute inhibition of the betaine transporter by ATP and adenosine in renal MDCK cells. Am J Physiol Renal Physiol 2008;295:F108-F117.

25 Kempson SA, Edwards JM, Sturek M: Inhibition of the renal betaine transporter by calcium ions. Am J Physiol Renal Physiol 2006;291:F305-F313.

26 Bitoun M, Tappaz M: Gene expression of taurine transporter and taurine biosynthetic enzymes in brain of rats with acute or chronic hyperosmotic plasma: A comparative study with gene expression of myo-inositol transporter, betaine transporter and sorbitol biosynthetic enzyme. Brain Res Mol Brain Res 2000;77:10-18.

-27 Lehre AC, Rowley NM, Zhou Y, Holmseth S, Guo C, Holen T, Hua R, Laake P, Olofsson AM, Poblete-Naredo I, Rusakov DA, Madsen KK, Clausen RP, Schousboe A, White HS, Danbolt NC: Deletion of the betaineGABA transporter (BGT1; slc6a12) gene does not affect seizure thresholds of adult mice. Epilepsy Res 2011;95:70-81.

28 Burnham CE, Buerk B, Schmidt C, Bucuvalas JC: A liver-specific isoform of the betaine/GABA transporter in the rat: cDNA sequence and organ distribution. Biochim Biophys Acta 1996;1284:4-8.

29 Weik C, Warskulat U, Bode J, Peters-Regehr T, Häussinger D: Compatible organic osmolytes in rat liver sinusoidal endothelial cells. Hepatology 1998;27:569-575.

-30 Wettstein M, Weik C, Holneicher C, Haussinger D: Betaine as an osmolyte in rat liver: metabolism and cellto-cell interactions. Hepatology 1998 27:787-793.

31 Häussinger D: Neural control of hepatic osmolytes and parenchymal cell hydration. Anat Rec A Discov Mol Cell Evol Biol 2004;280:893-900.

-32 Ferraris JD, Williams CK, Persaud P, Zhang Z, Chen Y, Burg MB: Activity of the TonEBP/OREBP transactivation domain varies directly with extracellular $\mathrm{NaCl}$ concentration. Proc Natl Acad Sci USA 2002;99:739-744. 
Kempson/Vovor-Dassu/Day: Role of Betaine Transport in Liver

33 Zhou Y, Holmseth S, Hua R, Lehre AC, Olofsson AM, Poblete-Naredo I, Kempson SA, Danbolt NC: The betaine-GABA transporter (BGT1, slc6a12) is predominantly expressed in the liver and at lower levels in the kidneys and at the brain surface. Am J Physiol - Renal Physiol 2012;302:F316-F328.

-34 Sacci JB: Hepatocyte perfusion, isolation and culture. Methods Mol Med 2002;72:503-505.

35 Kempson SA, Parikh V, Xi L, Chu S, Montrose M: Subcellular distribution of the renal betaine transporter during hypertonic stress. Am J Physiol Cell Physiol 2003;285:C1091-C1100.

-36 Hatanaka T, Hatanaka Y, Setou M: Regulation of amino acid transporter ATA2 by ubiquitin ligase Nedd4-2. J Biol Chem 2006;281:35922-35930.

-37 Koepsell H: The SLC22 family with transporters of organic cations, anions and zwitterions. Mol Aspects Med 2013;34:413-435.

38 Slow S, Lever M, Lee MB, George PM, Chambers ST: Betaine analogues alter homocysteine metabolism in rats. Int J Biochem Cell Biol 2004;36:870-880.

-39 Halsted CH, Medici V: Vitamin-dependent methionine metabolism and alcoholic liver disease. Adv Nutr 2011;2:421-427.

40 Mato JM, Corrales FJ, Lu SC, Avila MA: S-Adenosylmethionine: a control switch that regulates liver function. FASEB J 2002;16:15-26.

41 Jung YS, Kim SJ, Kwon DY, Ahn CW, Kim YS, Choi DW, Kim YC: Alleviation of alcoholic liver injury by betaine involves an enhancement of antioxidant defense via regulation of sulfur amino acid metabolism. Food Chem Toxicol 2013;62C:292-298.

42 Wang Z, Yao T, Song Z: Involvement and mechanism of DGAT2 upregulation in the pathogenesis of alcoholic fatty liver disease. J Lipid Res 2010;51:3158-3165.

43 Mato JM, Martinez-Chantar ML, Lu SC: Methionine Metabolism and Liver Disease. Annu Rev Nutr 2008;28:273-293.

44 Sozio M, Crabb DW: Alcohol and lipid metabolism. Am J Physiol Endocrinol Metab 2008;295:E10-E16.

-45 Ji C, Shinohara M, Kuhlenkamp J, Chan C, Kaplowitz N: Mechanisms of protection by the betainehomocysteine methyltransferase/betaine system in HepG2 cells and primary mouse hepatocytes. Hepatology 2007;46:1586-1596.

46 Medici V, Peerson JM, Stabler SP, French SW, Gregory Iii JF, Virata MC, Albanese A, Bowlus CL, Devaraj S, Panacek EA, Rahim N, Richards JR, Rossaro L, Halsted CH: Impaired homocysteine transsulfuration is an indicator of alcoholic liver disease. J Hepatol 2010;53:551-557.

47 Barak AJ, Beckenhauer HC, Tuma DJ: Betaine, ethanol, and the liver: A review. Alcohol 1996;13:395-398.

48 Kwon DY, Jung YS, Kim SJ, Park SJ, Park JH, Kim YC: Impaired sulfur-amino acid metabolism and oxidative stress in nonalcoholic fatty liver are alleviated by betaine supplementation in rats. J Nutr 2009;139:63-68.

49 Forestier M, Bänninger R, Reichen J, Solioz M: Betaine homocysteine methyltransferase: gene cloning and expression analysis in rat liver cirrhosis. Biochim Biophys Acta 2003;1638:29-34.

50 Nicholas PC, Kim D, Crews FT, Macdonald JM: 1H NMR-Based Metabolomic Analysis of Liver, Serum, and Brain Following Ethanol Administration in Rats. Chem Res Toxicol 2008;21:408-420.

51 Regan TJ, Haider B: Ethanol Abuse and Heart Disease. Circulation 1981;64:14-19.

-52 Waldenström A: Alcohol and congestive heart failure. Alcohol Clin Exp Res 1998;22:315S-317S.

-53 Spies CD, Sander M, Stangl K, Fernandez-Sola J, Preedy VR, Rubin E, Andreasson S, Hanna EZ, Kox WJ: Effects of alcohol on the heart. Curr Opin Crit Care 2001;7:337-343.

54 Kim SJ, Jung YS, Kwon DY, Kim YC: Alleviation of acute ethanol-induced liver injury and impaired metabolomics of S-containing substances by betaine supplementation. Biochem Biophys Res Commun 2008;368:893-898.

55 Gyamfi MA, Wan Y-JY: Pathogenesis of alcoholic liver disease: the role of nuclear receptors. Exp Biol Med 2010;235:547-560.

56 Stewart S, Jones D, Day CP: Alcoholic liver disease: new insights into mechanisms and preventative strategies. Trends Mol Med 2001;7:408-413.

57 West LJ, Maxwell DS, Noble EP, Solomon DH: Alcoholism. Ann Intern Med 1984;100:405-416.

-58 Abdelmalek MF, Angulo P, Jorgensen RA, Sylvestre PB, Lindor KD: Betaine, a promising new agent for patients with nonalcoholic steatohepatitis: results of a pilot study. Am J Gastroenterol 2001;96:2711-2717.

59 Craig SAS: Betaine in human nutrition. Am J Clin Nutr 2004;80:539-549.

60 Kaplowitz N, Ji C: Unfolding new mechanisms of alcoholic liver disease in the endoplasmic reticulum. J Gastroenterol Hepatol 2006;21:S7-9. 
61 Cave M, Deaciuc I, Mendez C, Song Z, Joshi-Barve S, Barve S, McClain C: Nonalcoholic fatty liver disease: predisposing factors and the role of nutrition. J Nutr Biochem 2007;18:184-195.

62 Eklund M, Bauer E, Wamatu J, Mosenthin R: Potential nutritional and physiological functions of betaine in livestock. Nutr Res Rev 2005;18:31-48.

63 Kathirvel E, Morgan K, Nandgiri G, Sandoval BC, Caudill MA, Bottiglieri T, French SW, Morgan TR: Betaine improves nonalcoholic fatty liver and associated hepatic insulin resistance: a potential mechanism for hepatoprotection by betaine. Am J Physiol Gastrointest Liver Physiol 2010;299:G1068-G1077.

64 Adams LA, Angulo P: Treatment of non-alcoholic fatty liver disease. Postgrad Med J 2006;82:315-322.

65 McGregor DO, Dellow WJ, Robson RA, Lever M, George PM, Chambers ST: Betaine supplementation decreases post-methionine hyperhomocysteinemia in chronic renal failure. Kidney Int 2002;61:10401046.

66 Atkinson W, Elmslie J, Lever M, Chambers ST, George PM: Dietary and supplementary betaine: acute effects on plasma betaine and homocysteine concentrations under standard and postmethionine load conditions in healthy male subjects. Am J Clin Nutr 2008;87:577-585.

67 Seshadri S, Beiser A, Selhub J, Jacques PF, Rosenberg IH, D'Agostino RB, Wilson PWF, Wolf PA: Plasma Homocysteine as a Risk Factor for Dementia and Alzheimer's Disease. N Engl J Med 2002;346:476-483.

68 Zhao Z, Yu M, Crabb D, Xu Y, Liangpunsakul S: Ethanol-Induced Alterations in Fatty Acid-Related Lipids in Serum and Tissues in Mice. Alcohol Clin Exp Res 2011;35:229-234. 